\title{
Do constrained immigration rates and high $\beta$ diversity explain contrasting productivity-diversity patterns measured at different scales?
}

\author{
Niall M. Connolly ${ }^{1,2} \cdot$ Richard G. Pearson $^{1}$ (1) \\ Received: 16 November 2019 / Accepted: 21 September 2020 \\ (c) Springer-Verlag GmbH Germany, part of Springer Nature 2020
}

\begin{abstract}
The relationship between productivity and diversity is controversial because of disparity between unimodal and monotonic patterns, especially when occurring simultaneously at different scales. We used stream-side artificial channels to investigate how the availability of a major resource (leaf litter) affected stream invertebrate abundance and diversity at leaf-pack and whole-channel scales. At the larger scale, invertebrate diversity increased monotonically with increasing litter resource density, whereas at the smaller scale the relationship was hump-shaped, in keeping with reports in the literature. This divergence at higher resource levels suggests that multiple mechanisms may be operating. Our results indicate that consistently high species turnover ( $\beta$ diversity) caused the monotonic pattern because of a species-area or "sampling effect" in which new species accumulate with increasing number of samples. The hump-shaped pattern was due to constrained immigration because of a "dilution effect" in which a limited number of immigrants is spread out among the increasing number of available patches. We propose that the relationship between productivity or resource availability and $\alpha$ diversity is generally hump-shaped and the scale-dependent contrast in the relationship only arises where the species pool is large and $\beta$ diversity is high. Differences in $\beta$ diversity may, therefore, explain some of the contrasting patterns in the productivity-diversity relationship previously reported.We suggest that continuing immigration by rare taxa is important in sustaining species diversity when productivity is high. The hump-shaped pattern has implications for the impact of anthropogenic ecosystem enrichment on species diversity.
\end{abstract}

Keywords Sampling effect $\cdot$ Dilution effect $\cdot$ Monotonic pattern $\cdot$ Humped pattern $\cdot$ Stream assemblage

Communicated by David Chalcraft.

Electronic supplementary material The online version of this article (https://doi.org/10.1007/s00442-020-04766-x) contains supplementary material, which is available to authorized users.

Richard G. Pearson

richard.pearson@jcu.edu.au

Niall M. Connolly

Niall.Connolly@daf.qld.gov.au

1 College of Science and Engineering, and TropWater, James Cook University, Townsville, QLD 4811, Australia

2 Present Address: Queensland Department of Agriculture and Fisheries, Townsville 4814, Australia

\section{Introduction}

Unravelling the mechanisms that determine the relationship between productivity or resource availability and diversity (here meaning species richness) is important in understanding biodiversity and how to conserve it (Huston 1979; Pierce 2014; Gross 2016). However, the effects of productivity on community composition are not predictable, except perhaps under extreme oligotrophic or eutrophic conditions (Vitousek et al. 1997; Smith et al. 1999). In some cases diversity increases monotonically with productivity (Currie and Paquin 1987; Gaston 2000; Cardinale et al. 2009); in others the relationship is unimodal, or "hump-shaped", with maximum diversity at intermediate productivity (e.g., Adler et al. 2011; Pierce 2014; Fraser et al. 2015). Much research has focussed on explaining the decline in diversity under high productivity (Tilman and Pacala 1993; Dodson et al. 2000). Monotonic and humped relationships may occur in the same community at different scales (Waide et al. 1999; 
Gross et al. 2000; Korhonen et al. 2011): for example, the diversity of invertebrates inhabiting ponds increases monotonically with productivity at regional scales (among watersheds) but the relationship is humped at local scales (among ponds) (Chase and Leibold 2002). Explanations for the different patterns have been put forward-for example, Chase and Leibold (2002) invoked a role for $\beta$ diversity; however, the mechanisms have yet to be adequately substantiated to explain the humped relationship, let alone the disparity between unimodal and monotonic patterns (e.g., Tilman and Pacala 1993; Abrams 1995; Kadmon and Benjamani 2006; Xiao et al. 2010), or how both patterns could emerge at different scales in the same community (Chase and Leibold 2002).

The monotonic pattern may occur because productivity promotes coexistence and hence biodiversity (e.g., Michalet et al. 2006; Xiao et al. 2009). Abrams (1995) suggested that (1) increased productivity might raise the abundance of rare species, reducing their extinction rates; (2) increased productivity might increase the abundance of rare resources that are required by specialist species; (3) intraspecific density-dependent processes, such as interference or predation, increase with productivity, allowing species to coexist rather than be competitively excluded (explained by Abrams 1983); (4) spatial heterogeneity in the supply of resources decreases with increasing productivity, which tends to exclude microhabitats of limited extent, and so decreases diversity through competitive exclusion (cf. Tilman \& Pacala 1993; Fraser et al. 2015); and (5) higher productivity increases extinction rates and decreases colonisation rates in a system in which coexistence is a trade-off between the ability of arrivals to colonise and their competitive ability, as would be predicted by island biogeography theory (McArthur and Wilson 1967).

The unimodal pattern may result from straightforward neutral processes. For example, Kadmon and Benjamini (2006) found increasing abundance and decreasing extinctions and, therefore, increasing diversity, under low to moderate productivity. However, with higher productivity, diversity decreased because increased reproduction reduced the relative frequency of novel colonisers (i.e., the novel immigrants were "diluted" by increasing numbers of locally recruited competitors), thereby creating the hump-shaped relationship.

Geographic scale influences the productivity-diversity relationship, with a monotonic pattern at large scales and a unimodal pattern at small scales (Oksanen 1996; Mittlebach et al. 2001; Chase and Leibold 2002; Chalcraft et al. 2004; Tonkin and Death 2013), although Fraser et al. (2015) reported a unimodal pattern at the global scale. An exception in the literature is the observation by Chase and Leibold (2002) of a monotonic relationship at regional scales and a unimodal pattern at local scales in the same assemblage. Chase (2010) proposed that for these relationships to occur simultaneously, $\beta$ diversity (variation among local sites) would have to increase with productivity. As $\beta$ diversity is influenced by community assembly mechanisms, at least one of these mechanisms would need to change with productivity to create the relationship and influence regional $(\Upsilon)$ diversity. These mechanisms include deterministic processes, in which habitat heterogeneity leads to niche diversification across localities; stochastic process such as ecological drift, dispersal limitation, and different colonisation and extinction dynamics across localities; or the interaction between deterministic and stochastic variation leading to more deterministic priority effects that vary across localities (Fukami $\&$ Morin 2003; Chase 2010). Chase (2010) suggested that it was more likely that the variation in the importance of stochastic processes increased $\beta$ diversity with productivity in pond communities because purely deterministic processes filter out unsuitable taxa in harsh environments, whereas in productive environments stochastic processes due to differential colonisation history and priority effects will have a greater influence, leading to multiple stable equilibria and greater representation of the regional pool.

It is evident that there is no adequate explanation for mechanisms that might produce co-occurrence of unimodal and monotonic diversity patterns in the same community under different levels of resources. We aimed to address this issue by investigating the effect of resource enrichment on a stream invertebrate assemblage. We examined the relationship in a largely detrital food web, dependent mainly on riparian leaf litter input and the associated biomass of microbes and deposited fine organic material (Fisher and Likens 1972; Rosemond et al. 2001; Cheshire et al. 2005; Connolly and Pearson 2013). As well as providing food sources, leaf litter provides complex microhabitat, and both types of resource contribute to productivity, as judged by, for example, invertebrate abundance (Richardson 1992; Dudgeon and Wu 1999; Pearson and Connolly 2000; Connolly and Pearson 2018). We established density gradients of terrestrial leaf litter in streamside artificial stream channels to represent a gradient in productivity and measured the response of the invertebrate assemblage. We had previously shown that colonisation by drifting invertebrates was rapid and that there was high turnover of individuals, especially of rarer species, and that loss of individuals by drift was compensated for by continuous supply from upstream (Connolly and Pearson 2018). We, therefore, investigated the relationship between species diversity and the resource gradient at two scales-on individual leaf packs within channels, and across channels with different leaf-pack densities. We hypothesised that the relationships were positive, negative, or hump-shaped. We then determined the mechanisms for the observed relationships. We follow the lead of previous reports (see above) regarding different patterns at different scales by applying essentially a productivity-diversity 
model. We did not pursue a metacommunity model (e.g., Economo and Keitt 2008) because our litter patches were all highly connected by invertebrate drift, as is the case within riffles naturally (e.g., Benson and Pearson 1987; Bunn and Hughes 1997; Connolly and Pearson 2018), and because metacommunity studies of streams generally use the whole riffle or stream as the base unit (e.g., Tonkin et al. 2016; Heino et al. 2017; Crabot et al. 2020).

\section{Methods}

\section{Experimental set-up and sampling}

The experiment was undertaken in artificial stream channels located beside Birthday Creek in the Australian Wet Tropics bioregion $\left(19.00^{\circ} \mathrm{S}, 146.18^{\circ} \mathrm{E}\right.$; altitude $\left.880 \mathrm{~m}\right)$, in rainforest with complete canopy cover. The climate at the site is seasonal, with a warm wet season (December-April) and cooler dry season (May-November). The experiment was undertaken from December 3, 1999 to January 2, 2000, before any major storms had occurred. Water temperature during the study ranged from 20 to $25^{\circ} \mathrm{C}$, pH was $\sim 6.9$ and conductivity $\sim 35 \mu \mathrm{S} \mathrm{cm}{ }^{-1}$. The channels were $2400 \mathrm{~mm}$ long, $140 \mathrm{~mm}$ wide and $100 \mathrm{~mm}$ deep, constructed from PVC and fixed to a galvanised steel frame. Stream water was supplied to the channels from above a waterfall via a polyethylene pipe and a header tank, from which $20-\mathrm{mm}$ pipes supplied each channel at $6.0 \mathrm{~L} \mathrm{~min}^{-1}$. Each channel comprised three sections, separated by v-notch weirs to maintain water depths at approximately $70 \mathrm{~mm}$. A coarse filter (20-mm mesh) on the inlet of the header tank prevented clogging by whole leaf litter, but allowed passage of smaller suspended material including drifting animals. Invertebrates colonised the channels via drift from upstream, but could not enter from downstream. While aerial colonisation was possible, there was no evidence of it during the experiments (e.g., no influxes of first-instar individuals of particular taxa). The channels' substrata are rapidly colonised by a diverse assemblage of macroinvertebrates and simulate stream conditions well (Pearson and Connolly 2000; Connolly and Pearson 2007, 2013, 2018).

Thirty granite cobbles (diam. 60-70 mm, $\varphi=-6$ ) were collected from the stream, scrubbed and distributed along each channel to simulate stream substratum. A gradient in leaf litter cover was established by manipulating small packs of Apodytes brachystylus F. Muell. (Icacinaceae) leaves. Leaf packs consisted of approximately $2.5 \mathrm{~g}$ of airdried freshly collected leaves from a single tree, which were attached to individual cobbles using plastic tags and a rubber band. Leaves of this species are colonised by a diverse community of invertebrates and are readily consumed (Nolen and Pearson 1993; Pearson and Connolly 2000; Connolly and Pearson 2013, 2018). The exact mass of each pack was recorded. Treatments comprised different levels of leaf litter cover (from 0 to $100 \%$ of 30 cobbles with a leaf pack attached); positions for leaf packs were assigned randomly and treatments were distributed randomly among channels. The starting configuration included 20 channels, with three replicates each for $0 \%, 20 \%, 40 \%, 60 \%, 80 \%$ and $100 \%$ litter cover and one channel each for $10 \%$ and $50 \%$ cover. However, resources limited our processing capacity, so we selected at random one each of the replicated channels, plus the single $10 \%$ channel (Fig. 1).

The 40-day duration of the experiment allowed for adequate colonisation by invertebrates (Connolly and Pearson 2018), but was not long enough for leaf packs to degrade (Pearson and Connolly 2000; Connolly and Pearson 2013).
Fig. 1 Layout of artificial stream channels showing leaflitter patch resource gradient. Actual positions of treatments were randomised
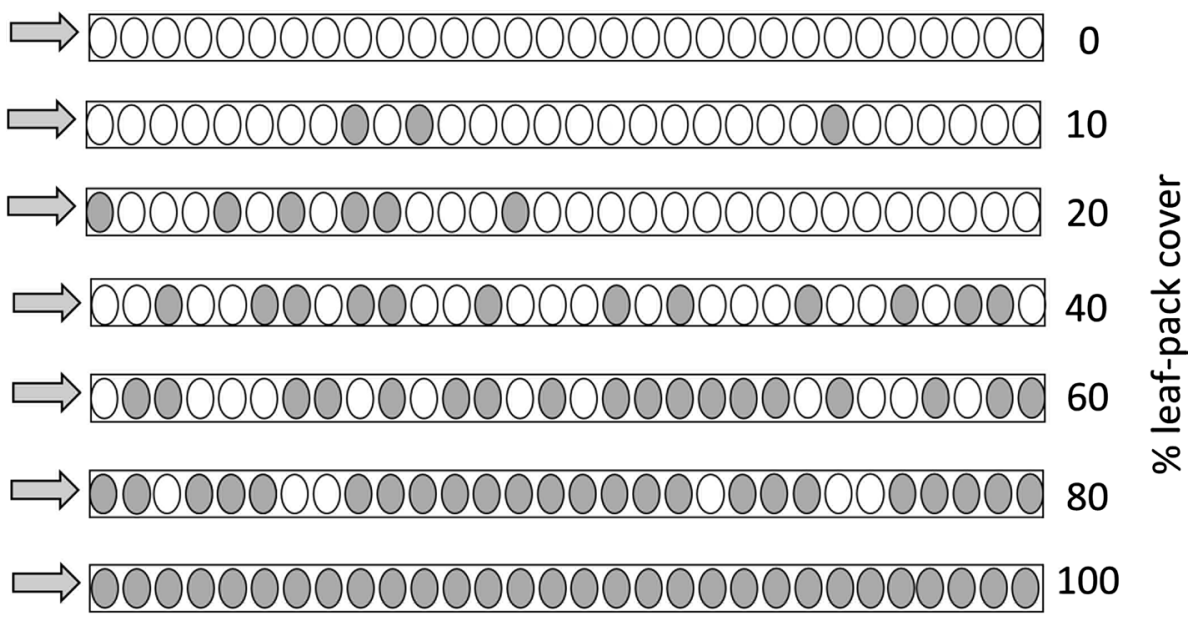

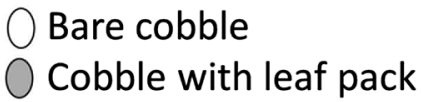


We previously showed that accumulation of abundance and richness on leaf packs in the artificial channels plateaued at around 24 days and then remained stable up to the 38-day duration of the experiments as a result of the equilibrium between local immigration and emigration (whether active or passive-i.e., local colonisation and extinction) (Connolly and Pearson 2018). At the end of the present experiment, all cobbles and cobble/leaf-pack combinations were removed in sequence from downstream to upstream, with cobbles and leaf packs, when present, placed in separate plastic containers, and labelled with the channel number, treatment and position within the channel (1-30). Individual leaves of the leaf packs were rinsed over a $63-\mu \mathrm{m}$-mesh sieve and invertebrates were removed and preserved in $80 \%$ ethanol. The remaining leaf material was air dried and weighed in the laboratory. Invertebrates were identified to genus or species where possible, or to higher taxa, and counted. Invertebrates were assigned to one of four functional feeding groups to investigate whether the proportion of predators increased with productivity. The four groups were: detritivorous collector/gatherers, grazer/scrapers, leaf and wood shredders and predators, assigned primarily following Cheshire et al. (2005), who described invertebrate diets in Birthday Creek, and secondarily following the Australian Centre for Freshwater Ecosystems (2020).

\section{Statistical analysis}

Abundance and diversity of invertebrates were investigated at two scales: individual cobble (with or without leaf pack) within channels; and whole channel (the sum of invertebrates from all 30 cobbles and cobble/leaf-pack combinations). We undertook regression analysis to describe the shape of relationships. Linear, sigmoidal, exponential and peak regression models were fitted to plots of the number of individuals and the number of taxa vs. the proportion of leaf leaf-pack cover at channel and leaf-pack scales in SigmaPlot v. 12.5 (Systat Software, San Jose, California, USA). We then selected the model that best fit the data, as indicated by the values of $r^{2}$. To further test for unimodal relationships, two methods were used. First, the Gaussian function of the form $f(x)=a^{*} \exp \left\{-0.5\left((x-b)^{2} / c^{2}\right)\right\}$, where $a$ is the height of the curve's peak, $b$ is the position of the centre of the peak and $c$ the standard deviation (which controls the width of the curve), was fitted using SigmaPlot to test if the curvilinear form of these relationships approximated a concave quadratic function. Second, we used a test developed by Mitchell-Olds and Shaw (1997) (the "MOS test") to determine whether relationships had an internal maximum (i.e., were hump-shaped) using generalised linear models (glim) with a log link function in $R$ (R Core Team 2015), following Mittlebach et al. (2001) and Chase and Leibold (2002).
We used regression analysis in SigmaPlot (exponential decay model had the best fit) to investigate the relationship between the proportion of predators in the assemblages and leaf pack density, to check whether density of predators increased with available resources, part of Abrams' (1995) suggestion (3) regarding a monotonic relationship. Linear regression analysis was used to describe the relationship between abundance and diversity within channels.

As an index of $\beta$ diversity, we used PCORD (version 6.20; MjM Software, Gleneden Beach, Oregon, USA) to calculate dissimilarity from presence/absence data as $1-C$, where $C$ is Jaccard's index (following Chase and Leibold 2002), and from log-abundance data as Bray-Curtis dissimilarity. We plotted the mean of pairwise dissimilarities within each leaf-pack density treatment against the gradient of leaf-pack density to determine whether the productivity-diversity relationship varied with scale as a result of increasing dissimilarity with productivity (Chase and Leibold 2002). Ordination was undertaken in PCORD using non-metric multidimensional scaling (NMDS) to illustrate sample relationships and we regressed axis scores against leaf litter density in SigmaPlot. We tested for differences in within-treatment dispersion of similarities among leafpack treatments using PERMDISP (in Primer, ver. 6.1.2, PRIMER-E Ltd, Plymouth, UK).

\section{Results}

A total of 31,685 animals and 76 taxa were collected in the channels (Online Resource Tables S1 and S2), but overall abundance was largely determined by a few taxa, notably Oligochaeta, Cladocera, Copepoda, Hydracarina (not identified further) and several species of Chironomidae. Also common were species of Plecoptera, Ephemeroptera, Simuliidae and Elmidae. Seventeen species of Trichoptera were collected but were never abundant.

Total abundance of invertebrates and total number of taxa per channel increased monotonically with \% leaf-pack cover (Fig. 2a, b). The shape of the relationship was curvilinear, with the rate of increase in the number of taxa declining towards $100 \%$ leaf-pack cover. In contrast, the abundance and number of taxa per cobble/leaf pack was unimodal or hump-shaped (Fig. 2c, d), confirmed by fitting the Gaussian function (for abundance, $F_{2,92}=5.604, P=0.0051$; for number of taxa, $\left.F_{2,92}=9.348, P=0.0001\right)$ and the MOS test (for hump at maximum: for abundance, $F_{2,92}=5.25$, $P=0.024$; for number of taxa, $\left.F_{2,92}=5.81, P=0.016\right)$. The relationships of invertebrate abundance and diversity with leaf-pack cover were similar whether considering only the cobbles with leaf packs attached or all cobbles (Fig. S1a, b). Abundance and number of taxa on cobbles without leaf packs were similar across treatments and much lower than 
(a)

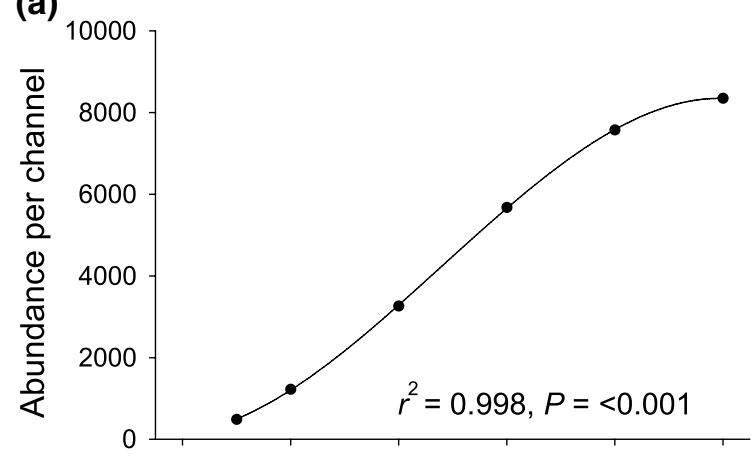

(c)

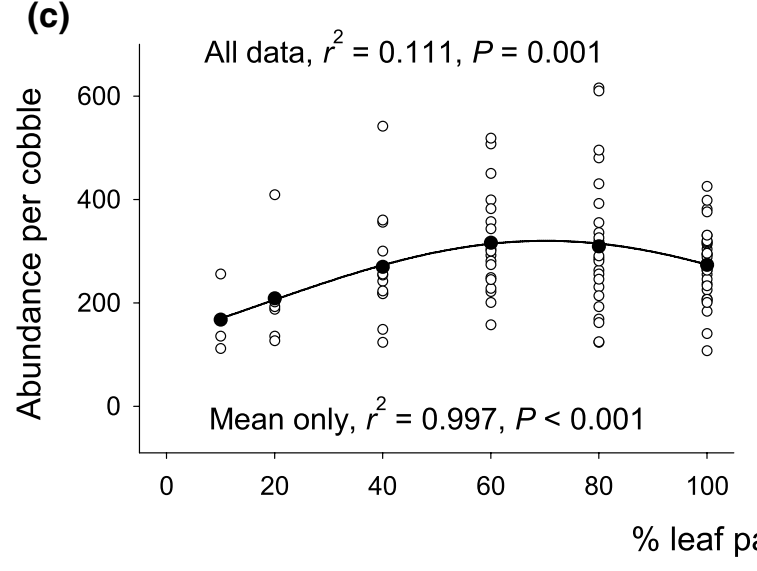

(b)

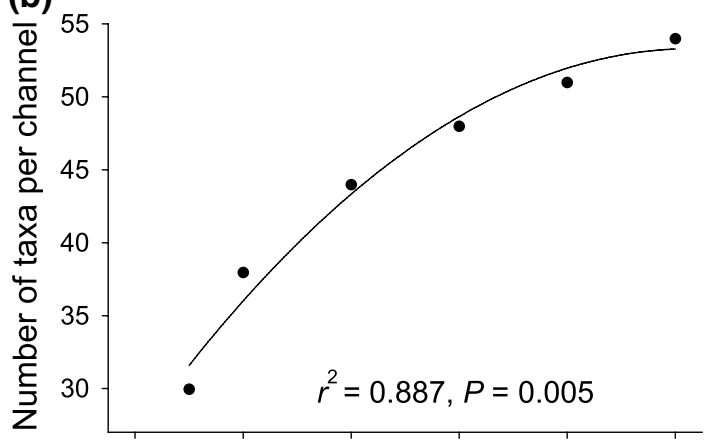

(d)

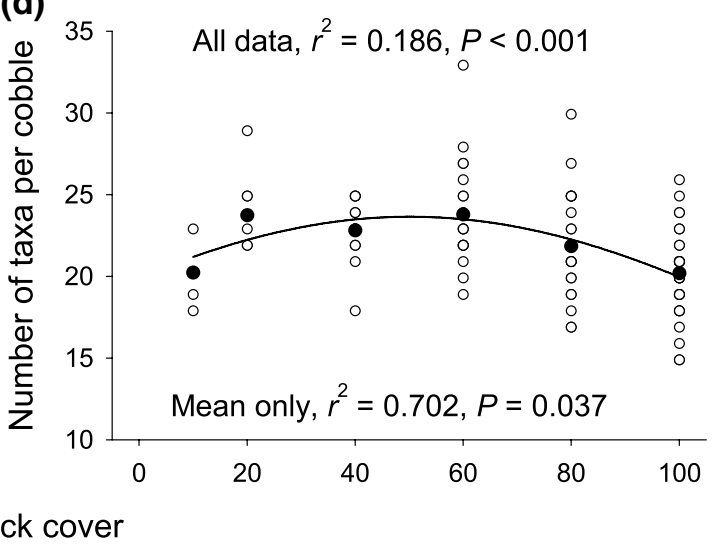

Fig. 2 Relationship between leaf-pack cover in artificial stream channels and a cumulative abundance of invertebrates on cobbles with leaf packs at the channel scale; $\mathbf{b}$ cumulative number of taxa on cobbles with leaf packs at the channel scale; $\mathbf{c}$ number of invertebrates (shaded circle) and mean number (unshaded circle) on individual

the cobble/leaf-pack combination (abundance, 3- to 10-fold lower; taxa about twofold lower; Fig. S1c, d). However, although an increase of total abundance and number of taxa per cobble appeared to start tailing off similarly, a peak was not reached, so the relationship was not unimodal (Fig. S1e, f). The the proportion of predators on leaf packs declined with leaf pack density (Fig. S2). $\beta$ diversity (dissimilarity between paired leaf packs) increased with leaf-pack cover initially, then remained constant apart from a dip at $100 \%$ cover for the presence-absence relationship (Fig. 3). Ordination showed a clear shift in assemblage composition with \% leaf-pack cover (Fig. 4), with a strong relationship between the mean axis-1 score and litter-pack density $\left(r^{2}=0.988\right)$. However, the spread of variation in composition amongst leaf packs within channel treatments did not increase across this gradient (PERMDISP analysis, pseudo- $F=0.648$, $P=0.856$; all pairwise differences with $P>0.147$ ). There were clear longitudinal gradients in the number of individuals and number of taxa on cobble/leaf packs within the channels, but the slope of the relationships varied along the leafpack resource gradient: abundance mostly increased with cobbles with leaf packs; and $\mathbf{d}$ number of taxa (shaded circle) and mean number (unshaded circle) on cobbles with leaf packs. Regression lines and statistics are shown: sigmoid model in a, exponential rise to maximum in $\mathbf{b}$, and peak models in $\mathbf{c}$ and $\mathbf{d}$

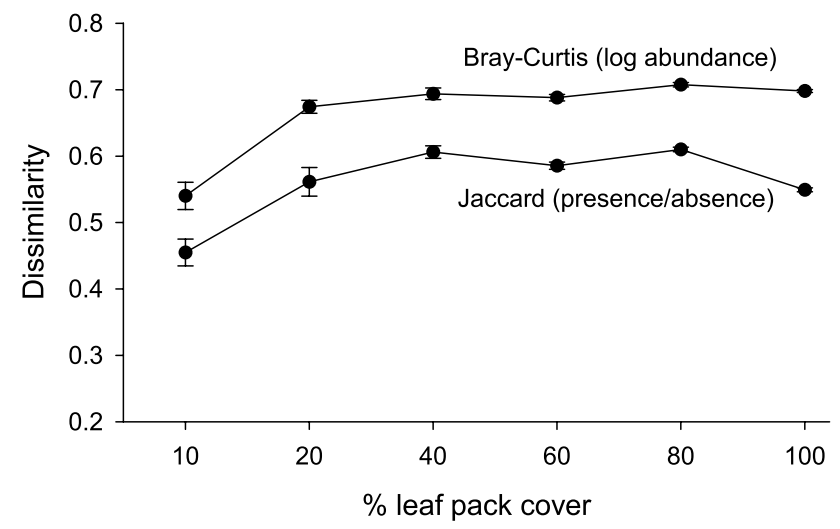

Fig. 3 Relationship of $\beta$ diversity (Jaccard and Bray-Curtis dissimilarity, mean $\pm \mathrm{SE}$ ) between leaf packs within leaf-pack treatments (\% cover) in artificial stream channels. If dissimilarity $=0$, then all taxa are shared among assemblages; if dissimilarity $=1$, then no taxa are shared among them 


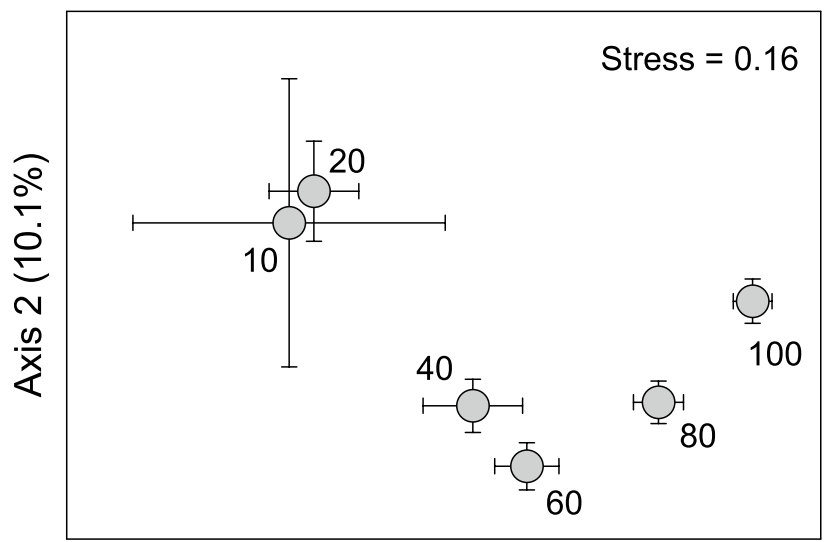

Axis $1(78.5 \%)$

Fig. 4 NMDS plot of assemblage composition showing centroids \pm SE for each treatment (10-100\% leaf-pack cover) in artificial stream channels. In regression of axis-1 score vs. litter-pack density, $r^{2}=0.9884, P<0.001$

distance downstream (Fig. 5), whereas diversity increased with distance downstream in the channel at $20 \%$ leaf-pack cover, but then gradually shifted with increasing cover to a negative relationship at $80 \%$ and $100 \%$ cover (Fig. 5). There was a strong relationship between the number of taxa and abundance at the channel scale (Fig. 6). The relationship between abundance and the number of taxa on individual leaf packs was positive in the 10 and $20 \%$ leaf-pack treatments ( $r^{2}=0.999$ and 0.833 , respectively) but absent in the other treatments $\left(r^{2}=0.000-0.029\right)$ (Fig. S3), corresponding with the shifts in gradients shown in Fig. 5.

\section{Discussion}

The artificial stream channels were colonised by a diverse assemblage of macroinvertebrates, as previously (Connolly and Pearson 2018). Despite the low number of channels, strong patterns in invertebrate abundance and diversity were evident. At the channel scale, invertebrate diversity increased with leaf-pack cover, consistent with a number of studies reporting the relationship between productivity and diversity at larger scales (e.g., Currie and Paquin 1987; Gaston 2000). However, the rate of increase in diversity in our channels declined towards $100 \%$ leaf-pack cover. Chase and Leibold (2002) reported that the relationship between productivity and diversity in ponds increased linearly at the regional scale, although their data suggest that the relationship was curvilinear, similar to the pattern we observed. Abrams (1995) similarly inferred that a monotonic relationship between productivity and diversity might level off as productivity increases and all available species are represented and analogous to a species accumulation curve resulting from increasing sampling effort.

At the leaf-pack scale, in contrast, diversity had a humpshaped relationship with leaf-pack cover, a pattern also reported in a number of studies (Rosenzweig and Abramsky 1993; Fraser et al. 2015). Therefore, our results indicate that the form of the productivity-diversity relationship varied with scale, concurring with Chase and Leibold (2002) and that the hump-shaped pattern was nested within the monotonic pattern within our confined system. We note that the unimodal relationship was not apparent when cobble and leaf litter pack samples were combined. The different relationships between the two sets of samples and litter pack density (unimodal for litter pack assemblages, consistent and flat for cobble assemblages), indicate that their assemblages differed and so obscurred the comparisons. Our focus was on the leaf litter packs as resource patches, and it is on those patches that we base our conclusions.

Previous explanations for the pattern of the productivity-diversity relationship (e.g., Abrams 1995; Chase 2010; Xiao et al. 2010) do not indicate how the two patterns can occur in the same assemblage at different scales (Chase and Leibold 2002). In our study, the correlation between abundance and diversity at the channel scale supports Abrams' (1995) first (and simplest) explanation that increased productivity might raise the abundance of rare species, reducing their extinction rates. As a monotonic relationship at the channel scale resulted from manipulation of a uniform resource, it is unlikely that increased diversity resulted from specialist niches, Abram's second suggested mechanism. With regard to his third mechanism (the effects of density-dependent processes), first, we have shown here that there was a decrease in density of predators rather than the increases that he proposed. Second, although intraspecific density-dependent interference has been demonstrated for invertebrates that shred leaves at our study site (Boyero and Pearson 2006), we have no information on whether it affects diversity. However, it is possible that intraspecific and interspecific competition limit invertebrate abundance, leading to the sigmoid curve at maximum resource density.

Nevertheless, the occurrence of monotonic and unimodal patterns in the same assemblage at different scales suggests that multiple priority mechanisms operate, beyond competitive or other biotic interactions. We explored the concept that, for the two patterns to occur in the same assemblage, $\beta$ diversity would have to increase with productivity (Chase and Leibold 2002; Chase 2010). In our stream channels, we have shown previously that rapid colonisation and dispersal indicate that the invertebrate assemblage is in a dynamic flux that results in assemblage stability at the small (leaf-pack) scale, as the colonising assemblage stabilised at 24 days (Connolly and Pearson 2018). Similarly, ordination indicated 
Fig. 5 Regressions of abundance (left-hand panels) and richness (right-hand panels) for each leaf pack and each leaf-pack density (10-100\%) in artificial stream channels
Abundance

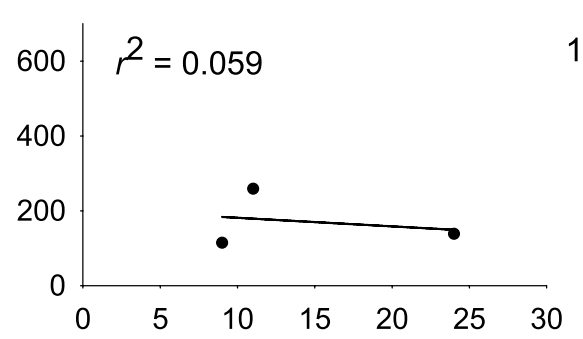

$10 \%$

Richness
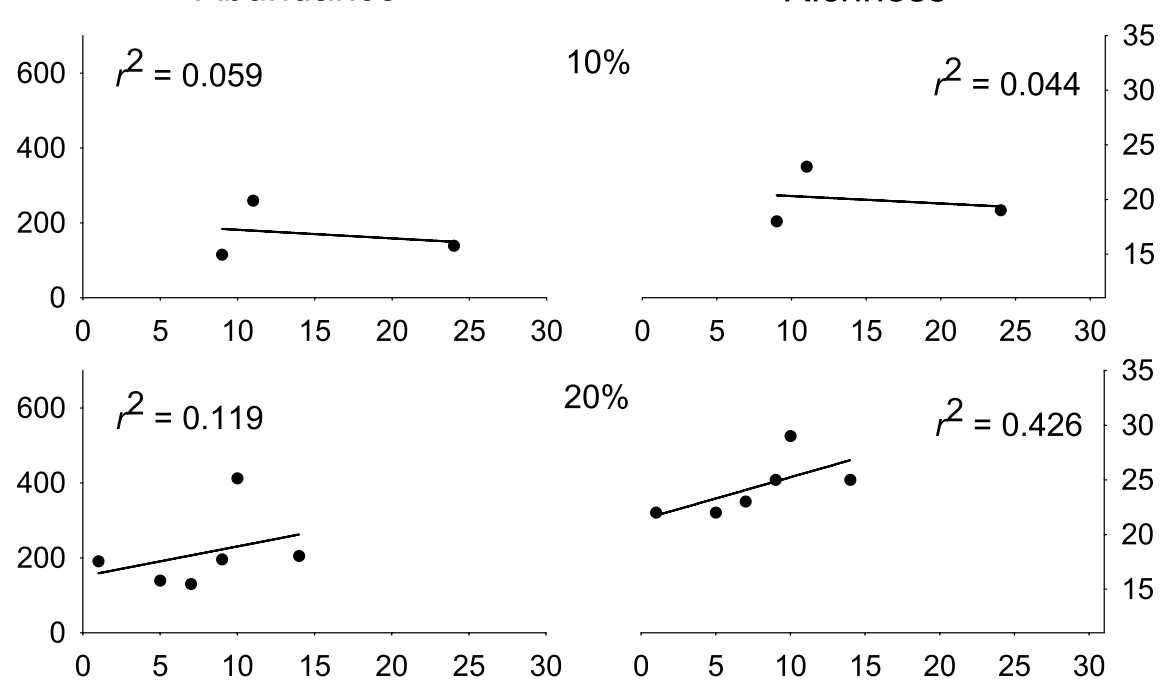

$20 \%$
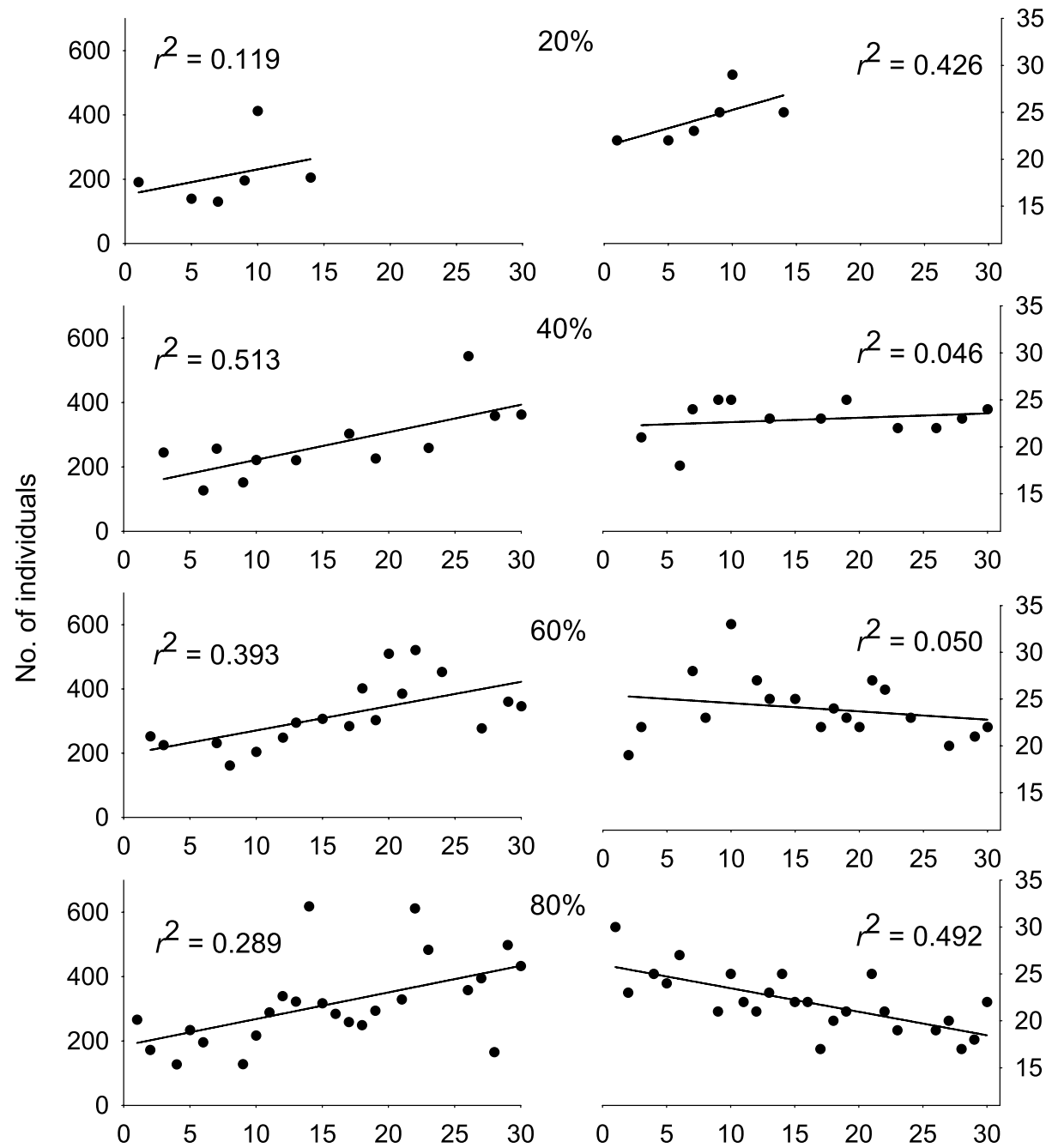
0 5 15 35 $80 \%$
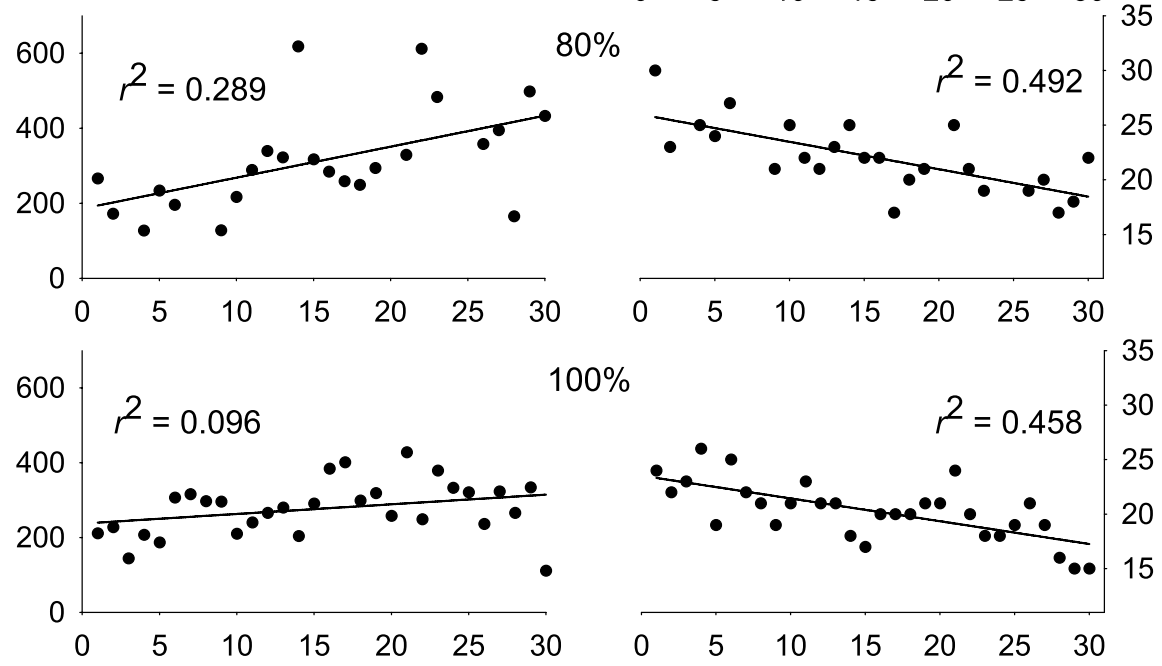

Pack number 


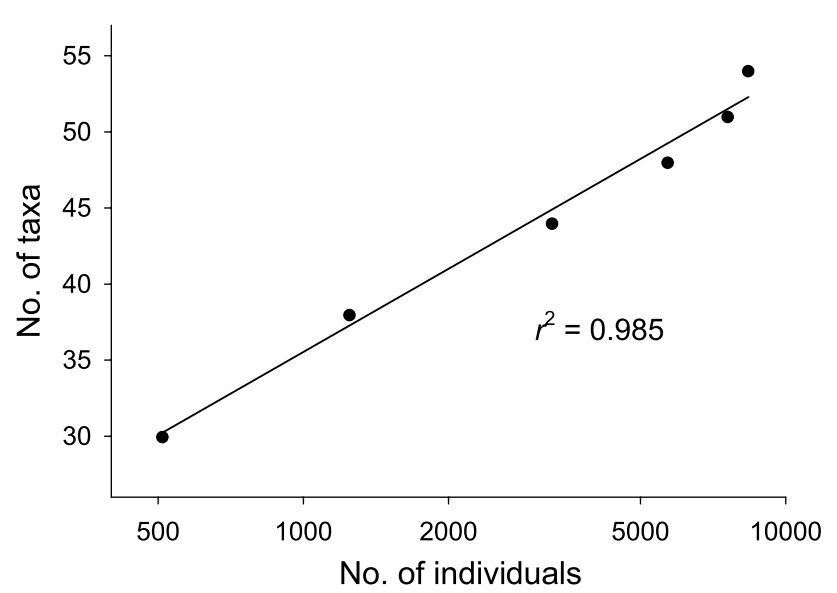

Fig. 6 Relationship between richness and abundance (log scale) summed across leaf packs within each artificial stream channel

a progressive shift in assemblage composition and a convergence at 24 and 38 days (Connolly and Pearson 2018). These results indicate that priority effects did not influence composition during colonisation and hence do not support the suggestion that multiple stable equilibria explain the scale-dependent productivity-diversity relationship (Fukami and Morin 2003; Chase 2010). Our high rates of colonisation and dispersal suggest high temporal variance, which could give rise to multiple compositions at any point in time, resulting in local community dissimilarity ("mosaic cycles"-Fukami 2004). However, we found no increase in dissimilarity with increasing leaf-pack cover. Similarly, while Chase (2010) found a nested ordination pattern with increased variation with productivity, we showed a shift in assemblage composition with increasing leaf-pack cover, but with the variation in composition among leaf packs constant across the gradient.

The divergence between channel-scale and leaf-packscale richness at high \% leaf-pack cover suggests that there were new species occurring in leaf packs in the higher $\%$ cover treatments, but this divergence did not correspond to an increase in dissimilarity among leaf-pack samples. The dissimilarity values were generally high throughout, and the observed differences that cause to the hump-shaped pattern were small relative to the species pool. Our leaf packs represented habitat units, as well as a potential food source. Therefore, if dissimilarity is consistently high, maintained by a large species pool relative to the number of taxa on individual leaf packs, then adding more leaf packs would be expected to increase channel-scale $(\Upsilon)$ diversity. Consequently, at the channel scale, the monotonic pattern in the number of taxa versus leaf-pack cover was probably due to increased habitat area and a species-area or sampling effect, agreeing with Abrams' (1995) first explanation for a monotonic productivity-diversity relationship. But this does not explain why the number of taxa on individual leaf packs ( $\alpha$ diversity) declined at greater \% leaf-pack cover.

The number of invertebrates drifting into the artificial stream channels was determined by the water flow rate. The number of leaf packs in channels then determined the immigration probabilities at the leaf-pack scale, as they provided more habitat, but with a similar number of drifting macroinvertebrates entering each channel. But when there were few leaf packs in the channels, individuals were more easily lost, leading to a relatively high extinction (emigration) rate, keeping diversity low (Kadmon and Benjamini 2006). Intermediate levels of litter-pack cover led to an equilibrium between these processes. We have previously explained that the invertebrate assemblage inhabiting these leaf packs approximated an equilibrium model of immigration-emigration (Connolly and Pearson 2018). At higher leaf pack densities, there are insufficient immigrants to compensate for individuals lost. Therefore, the immigration-emigration dynamics, specifically a constrained immigration rate, could explain the decline in diversity on leaf packs in channels with high leaf-pack cover, and the discrepancy between the patterns at the larger and smaller scales.

This explanation is analogous to the dilution effect (Kadmon and Benjamini 2006), albeit dilution by immigrants rather than within-patch reproduction. It is also analogous to the hypothesis that in a community with a unimodal productivity-diversity relationship, species from sites with intermediate productivity have higher dispersal probabilities than species from sites with low or high productivity (Pärtel and Zobel 2007). A mechanism invoking constrained immigration also agrees with the suggestion that when dispersal rates are low unimodal patterns develop in both neutral and competing communities (Xiao et al. 2010). However, the neutral models used by Kadmon and Benjamini (2006) and Xiao et al. (2010) did not consider scale or $\beta$ diversity and how they might increase with productivity to produce different patterns for $\alpha$ and $\Upsilon$ diversity.

Abundance and diversity were correlated and their patterns were similarly scale-dependent, further suggesting that a simple sampling effect was driving diversity. The longitudinal gradients within the channels were probably due to differences in immigration rates across cobble/leafpack units, as the slope of the diversity gradient changed to negative at the peak of the "hump", indicating that more of the immigrants colonised the upstream than the downstream leaf packs, limiting the supply of immigrants downstream.

Pärtel and Zobel (2007) reported that the proportion of unimodal relationships increased with distance from the equator, but positive relationships were more common in the tropics because of larger species pools. Higher $\beta$ diversity and compositional variation across local sites will often occur where there is a large regional species pool ( $($ ) (Sabatini et al. 2018). It is possible that the relationship 
between productivity and $\alpha$ diversity is generally humpshaped because of reduced addition of new species to replace species lost though stochastic extinctions at high productivity. But a large species pool may increase the probability of high $\beta$ diversity, resulting in the large-scale relationship between productivity and $\Upsilon$ diversity being monotonic. In this regard, it is notable that Australian Wet Tropics streams, including Birthday Creek, have high invertebrate diversity compared with streams globally (Vinson and Hawkins 2004).

It is possible that the scale-dependent contrast in the productivity-diversity relationship only arises where $\beta$ diversity is high; in contrast, where $\beta$ diversity is low, a hump-shaped productivity-diversity relationship may be expected at both local and regional scales. Differences in $\beta$ diversity may, therefore, explain some of the contrasting patterns in the productivity-diversity relationship reported in the literature, which have made equivocal explanations for the relationship. While the hump-shaped productivity-diversity relationship has often been referred to as a local-scale pattern, it has also been reported at large (even global) scales (Fraser et al. 2015).

\section{Conclusions}

Despite a limited number of channels, the patterns we found in invertebrate abundance and richness were strong and require explanation. We conclude that the patterns may have been caused by a combination of sampling and dilution effects, but these conclusions need testing in different systems and at different spatial and temporal scales. A hump-shaped productivity-diversity relationship has significant implications for the conservation of species diversity because it points to the importance of considering $\beta$ diversity, and it predicts a decline in diversity at high productivity (Pierce 2014). It is neecessary to understand the processes that determine this relationship to be able to predict decline in diversity under scenarios of increasing productivity by anthropogenic fertilisation in both terrestrial and aquatic environments (Woodward et al. 2012). Our results suggest that maintaining the ability of rare taxa to immigrate is important in sustaining species diversity at high productivity.

Acknowledgements We thank L. Davis, M. Reilly, A. Cairns and F. Christidis for field and laboratory assistance, and R. Marchant, J. Davis, D. Calcraft and anonymous reviewers for comments that greatly improved the manuscript. This research was funded by the Cooperative Research Centre for Tropical Rainforest Ecology and Management at James Cook University.

Author contribution statement NC designed the study, with input from RP, and undertook data collection and initial drafting of the manuscript. Both authors contributed to analyses and drafting of the current manuscript.

\section{Compliance with ethical standards}

Conflict of interest The authors declare that they have no conflict of interest.

\section{References}

Abrams PA (1983) The theory of limiting similarity. Ann Rev Ecol Syst 14:359-376

Abrams PA (1995) Monotonic or unimodal diversity productivity gradients - what does competition theory predict. Ecology 76:2019-2027

Adler PB, Seabloom EW, Borer ET, Hillebrand H, Hautlier Y, Hector A, Harpole WS, O'Halloran LR, Grace JB, Anderson TM, Bakker JD, Biederman LA, Brown CS, Buckley YM, Calabrese LB, Chu CJ, Cleland EE, Collins SL, Cottingham KL, Crawley MJ, Damschen EI, Davies KF, DeCrappeo NM, Fay PA, Firn J, Frater P, Gasarch EI, Gruner DS, Hagenah N, Hille Ris Lanbers J, Humphries H, Jin VL, Kay AD, Kirkman KP, Lein JA, Knops JM, La Pierre KJ, Lambrinos JG, Li W, McDougall AS, McCulley RL, Melbourne BA, Mitchell CE, Morre JL, Morgan JW, Mortensen B, Orrock JL, Prober SM, Pyke DA, Risch AC, Schuetz M, Smith MD, Stevens CJ, Sullivan LL, Wang G, Wragg PD, Wright PD, Yang LH (2011) Productivity is a poor predictor of plant species richness. Science 333:1750-1752

Benson LJ, Pearson RG (1987) Drift and upstream movements of macroinvertebrates in a tropical Australian stream. Hydrobiologia 153:225-239

Boyero L, Pearson RG (2006) Intraspecific interference in a tropical stream shredder guild. Mar Freshw Res 57:201-206

Bunn SE, Hughes JM (1997) Dispersal and recruitment in streams: evidence from genetic studies. J N Am Benthol Soc 16:338-346

Cardinale BJ, Hillebrand H, Harpole WS, Gross K, Ptacnik R (2009) Separating the influence of resource "“availability" from resource "imbalance"" on productivity-diversity relationships. Ecol Lett $12: 475-487$

Centre for Freshwater Ecosystems (2020) Identification and ecology of Australian freshwater invertebrates. An interactive guide. Latrobe University https://www.mdfrc.org.au/bugguide/index .htm. Accessed 21 Mar 2020

Chalcraft DR, Williams JW, Smith MD, Willig MR (2004) Scale dependence in the species-richness-productivity relationship: The role of species turnover. Ecology 85:2701-2708

Chase JM (2010) Stochastic community assembly causes higher biodiversity in more productive environments. Science 328:1388-1391

Chase JM, Leibold MA (2002) Spatial scale dictates the productivitybiodiversity relationship. Nature 416:427-430

Cheshire K, Boyero L, Pearson RG (2005) Food webs in tropical Australian streams: shredders are not scarce. Freshw Biol 50:748-769

Connolly NM, Pearson RG (2007) The effect of fine sediment on tropical stream macroinvertebrate assemblages: a comparison using flow-through artificial stream channels and recirculating mesocosms. Hydrobiologia 592:423-438

Connolly NM, Pearson RG (2013) Nutrient enrichment of a heterotrophic stream alters leaf litter nutritional quality and shredder physiological condition via the microbial pathway. Hydrobiologia 718:85-92

Connolly NM, Pearson RG (2018) Colonisation, emigration and equilibrium of stream invertebrates in patchy habitats. Freshw Biol 63:1446-1456 
Crabot J, Heino J, Launay B, Datry T (2020) Drying determines the temporal dynamics of stream invertebrate structural and functional beta diversity. Ecography 43:620-635. https://doi.org/10.1111/ ecog.04835

Currie DJ, Paquin V (1987) Large-scale biogeographic patterns of species richness of trees. Nature 329:326-327

Dodson SI, Arnott SE, Cottingham KL (2000) The relationship in lake communities between primary productivity and species richness. Ecology 81:2662-2679

Dudgeon D, Wu KKY (1999) Leaf litter in a tropical stream: food or substrate for macroinvertebrates? Arch Hydrobiol 146:65-82

Economo EP, Keitt H (2008) Species diversity in neutral metacommunities: a network approach. Ecol Lett 11:52-62

Fisher SG, Likens GE (1972) Stream ecosystem: organic energy budget. Bioscience 22:33-35

Fraser LH, Pither J, Jentsch A, Sternberg M, Zobel M, Askarizadeh D, Bartha S, Beierkuhnlein C, Bennett JA, Bittel A, Boldgiv B, Boldrini II, Bork E, Brown L, Cabido M, Cahill J, Carlyle CN, Campetella G, Chelli S, Cohen O, Csergo A-M, Díaz S, Enrico L, Ensing D, Fidelis A, Fridley JD, Foster B, Garris H, Goheen JR, Henry HAL, Hohn M, Hassan Jouri M, Klironomos J, Koorem K, Lawrence-Lodge R, Long R, Manning P, Mitchell R, Moora M, Müller SC, Nabinger C, Naseri K, Overbeck GE, Palmer T, Parsons S, Pesek M, Pillar VD, Pringle RM, Roccaforte K, Schmidt A, Shang Z, Stahlmann R, Stotz GC, Sugiyama S, Szentes A, Thonpson D, Tungalag R, Undrakhbold S, van Rooyen M, Wellstein C, Wilson Zupo JBT (2015) Worldwide evidence of a unimodal relationship between productivity and plant species richness. Science 349:302-305

Fukami T (2004) Community assembly along a species pool gradient: implications for multiple-scale patterns of species diversity. Popul Ecol 46:137-147

Fukami T, Morin PJ (2003) Productivity-biodiversity relationships depend on the history of community assembly. Nature 424:423-426

Gaston KJ (2000) Global patterns in biodiversity. Nature 405:220-227

Gross KL (2016) Biodiversity and productivity entwined. Nature 529:293-294

Gross KL, Willig MR, Gough L, Inouye R, Cox SB (2000) Patterns of species density and productivity at different spatial scales in herbaceous plant communities. Oikos 89:417-427

Heino J, Soininen J, Alahuhta J, Lappalainen J, Virtanen R (2017) Metacommunity ecology meets biogeography: effects of geographical region, spatial dynamics and environmental filtering on community structure in aquatic organisms. Oecologia 183:121-137

Huston M (1979) A general hypothesis of species diversity. Am Nat 113:81-100

Kadmon R, Benjamini Y (2006) Effects of productivity and disturbance on species richness: A neutral model. Am Nat 167:939-946

Korhonen JJ, Wang J, Soininen J (2011) Productivity-Diversity relationship in lake plankton communities. PLoS ONE 6(8):e22041. https://doi.org/10.1371/journalpone0022041

MacArthur RH, Wilson EO (1967) The theory of island biogeography. Princeton University Press, Princeton

Michalet R, Brooker RW, Cavieres LA, Kikvidze Z, Lortie CJ, Pugnaire FI, Valiente-Banuet A, Callaway RM (2006) Do biotic interactions shape both sides of the humped-back model of species richness in plant communities? Ecol Lett 9:767-773

Mitchell-Olds T, Shaw RG (1997) Regression analysis of natural selection: statistical inference and biological interpretation. Evolution 41:1149-1161

Mittlebach GG, Steiner SF, Scheiner SM, Gross KL, Reynolds HL, Waide RB, Willig MR, Dodson SI, Gough L (2001) What is the observed relationship between species richness and productivity? Ecology 82:2381-2396
Nolen JA, Pearson RG (1993) Processing of litter from an Australian tropical stream by Anisocentropus kirramus Neboiss (Trichoptera: Calamoceratidae). Freshw Biol 29:469-479

Oksanen J (1996) Is the humped relationship between species richness and biomass an artefact due to plot size? J Ecol 84:293-295

Pärtel M, Zobel M (2007) Dispersal limitation may result in the unimodal productivity-diversity relationship: a new explanation for a general pattern. J Ecol 95:90-94

Pearson RG, Connolly NM (2000) Nutrient enhancement, food quality and community dynamics in a tropical rainforest stream. Freshw Biol 43:31-42

Pierce S (2014) Implications for biodiversity conservation of a lack of consensus regarding the humped-back model of species richness and biomass production. Funct Ecol 28:253-257

R Core Team (2015) R: A language and environment for statistical computing. R Foundation for Statistical Computing, Vienna, Austria. https://www.R-projectorg

Richardson JS (1992) Food, microhabitat, or both? Macroinvertebrate use of leaf accumulations in a montane stream. Freshw Biol 27:169-176

Rosemond AD, Pringle CM, Ramirez A, Paul MJ (2001) A test of top-down and bottom-up control in a detritus-based food web. Ecology 82:2279-2293

Rosenzweig ML, Abramsky Z (1993) How are diversity and productivity related? In: Ricklefs RE, Schluter D (eds) Species diversity in ecological communities: historical and geographical perspectives (pp. 52-65) University of Chicago Press, Chicago

Sabatini FM, Jiménez-Alfaro B, Burrascano S, Lora A, Chytrý M (2018) Beta-diversity of central European forests decreases along an elevational gradient due to the variation in local community assembly processes. Ecography 41:1038-1048

Smith VH, Tilman GD, Nekola JC (1999) Eutrophication: impacts of excess nutrient inputs on freshwater, marine, and terrestrial ecosystems. Environ Pollut 100:179-196

Tilman D, Pacala S (1993) The maintenance of species richness in plant communities. In Ricklefs RE, Schluter D (eds) Species diversity in ecological communities: historical and geographical perspectives. University of Chicago Press, Chicago, pp 13-25

Tonkin JD, Death RG (2013) Scale dependent effects of productivity and disturbance on diversity in streams. Fund Appl Limnol 182:283-295

Tonkin JD, Heino J, Sundermann A, Haase P, Jahnig SC (2016) Context dependency in biodiversity patterns of central German stream metacommunities. Freshw Biol 61:607-620

Vinson MR, Hawkins CP (2004) Broad-scalegeographical patterns in local stream insect genera richness. Ecography 26:751-767

Vitousek PM, Aber JD, Howarth RW, Likens GE, Matson PA, Schindler DW, Schlesinger WH, Tilman DG (1997) Human alteration of the global nitrogen cycle: sources and consequences. Ecol Appl 7:737-750

Waide RB, Willig MR, Steiner SF, Mittlebach G, Gough L, Dodson SI, Juday GP, Parmenter R (1999) The relationship between productivity and species richness. Annu Rev Ecol Syst 30:257-300

Woodward G, Gessner MO, Giller PS, Gulis V, Hladyz S, Lecerf A, Malmqvist B, McKie BG, Tiegs SD, Cariss H, Dobson M, Elosegi A, Ferreira V, Graça MAS, Fleituch T, Lacoursière JO, Nistorescu M, Pozo J, Risnoveanu G, Schindler M, Vadineanu A, Vought LB-M, Chauvet E (2012) Continental-scale effects of nutrient pollution on stream ecosystem functioning. Science 336:1438-1440

Xiao S, Michalet R, Wang GC (2009) The interplay between species' positive and negative interactions shapes the community biomassspecies richness relationship. Oikos 118:1343-1348

Xiao S, Zobel M, Szava-Kovats R, Partel M (2010) The effects of species pool, dispersal and competition on the diversity-productivity relationship. Glob Ecol Biogeogr 19:343-351 